\title{
Accuracy of Fine Needle Aspiration of the Thyroid in a University Teaching Hospital
}

\author{
Mohamed.Ahmed ${ }^{1}$, M.Jeffers ${ }^{2}$, M.Feeney $^{3}$, P.Govender $^{3}$, M.Sherlock ${ }^{1}$, and J.Gibney ${ }^{1}$ \\ Departments of Endocrinology ${ }^{1}$ Histopathology and Radiology ${ }^{3}$, The Adelaide and Meath Hospital , incorporating the National \\ Children's Hospital, Tallaght, Dublin, Ireland.
}

\section{OBJECTIVES}

Thyroid Fine needle aspiration (FNA) is a safe, valuable and cost effective procedure and is now regarded as the investigation of choice for preoperative assessment of thyroid nodules ${ }^{1}$.

The reported sensitivity of thyroid FNA varies from 65$98 \%$ and the specificity from 73 to $98 \%{ }^{2}$.

The aim of this study was to assess the accuracy of this procedure correlating cytology with histological outcomes, and to audit our practice against standard recommendations and published literature.

\section{METHODS}

The cytological diagnosis of all thyroid FNA biopsies performed in AMNCH during the 5 years period (2008-2012) was retrieved retrospectively from the pathology department laboratory information system (LIS).

Excel ${ }^{\circledR}$ spread sheets were compiled to generate a database, these data included: patient's demographics, cytological diagnosis using THY grading system, procedure guidance method i.e. ultrasound (US) guided or Free-hand aspiration, and the final histological diagnosis on those who undergone surgery.

Cytology results were placed into 5 diagnostic categories according to the RCPath criteria ${ }^{3}$.

Figure 1: Cytology outcomes according to THY classification

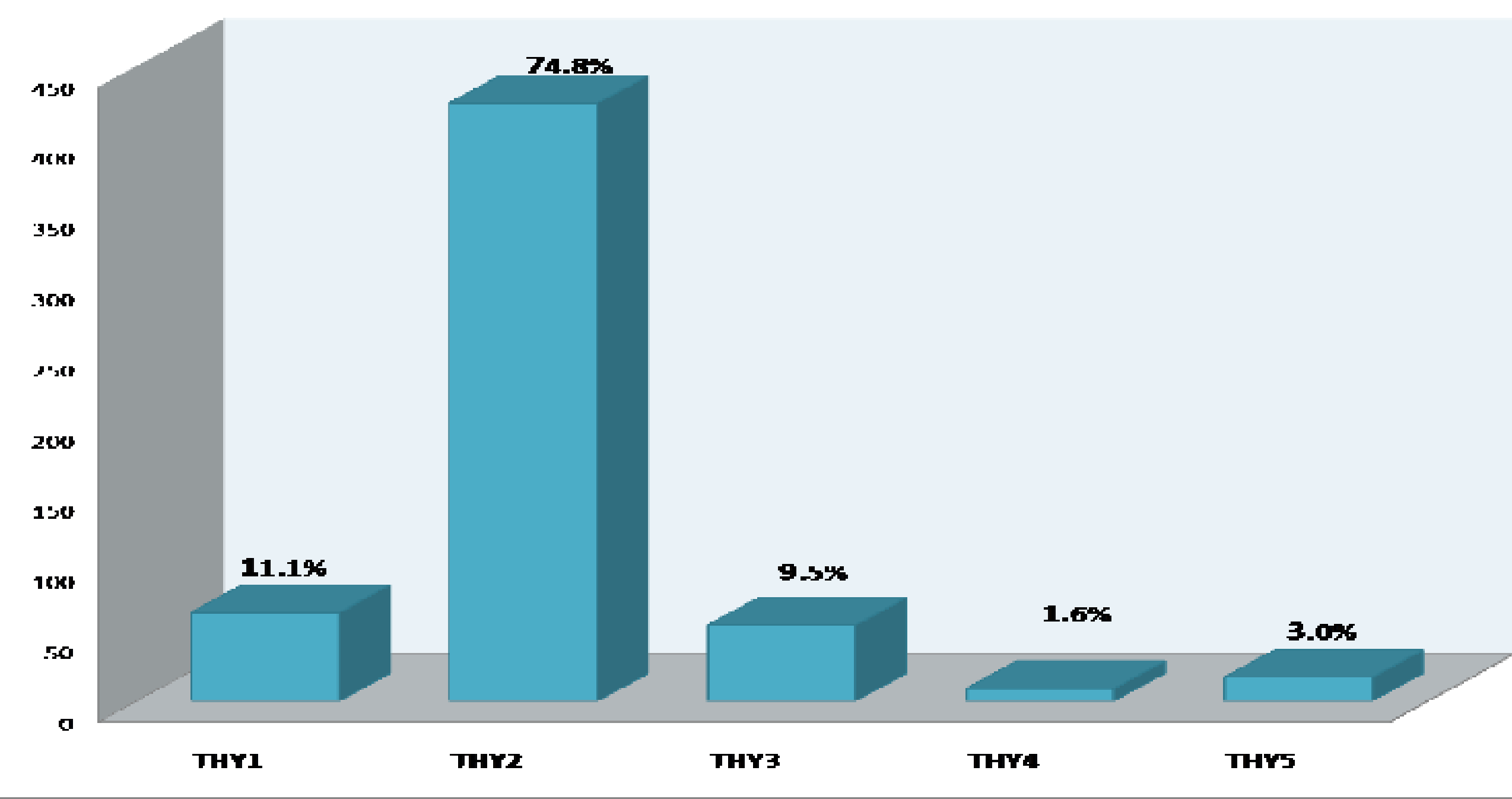

Table 1: Inadequacy rate according to guidance method.
FNAC Adequacy

Non Diagnostic Diagnostic Total

US guided $\quad 37(8.7 \%)$

Free-hand $\quad 17(15.7 \%)$
$386(91.3 \%) \quad 423$

$91(84.3 \% 0 \quad 108$

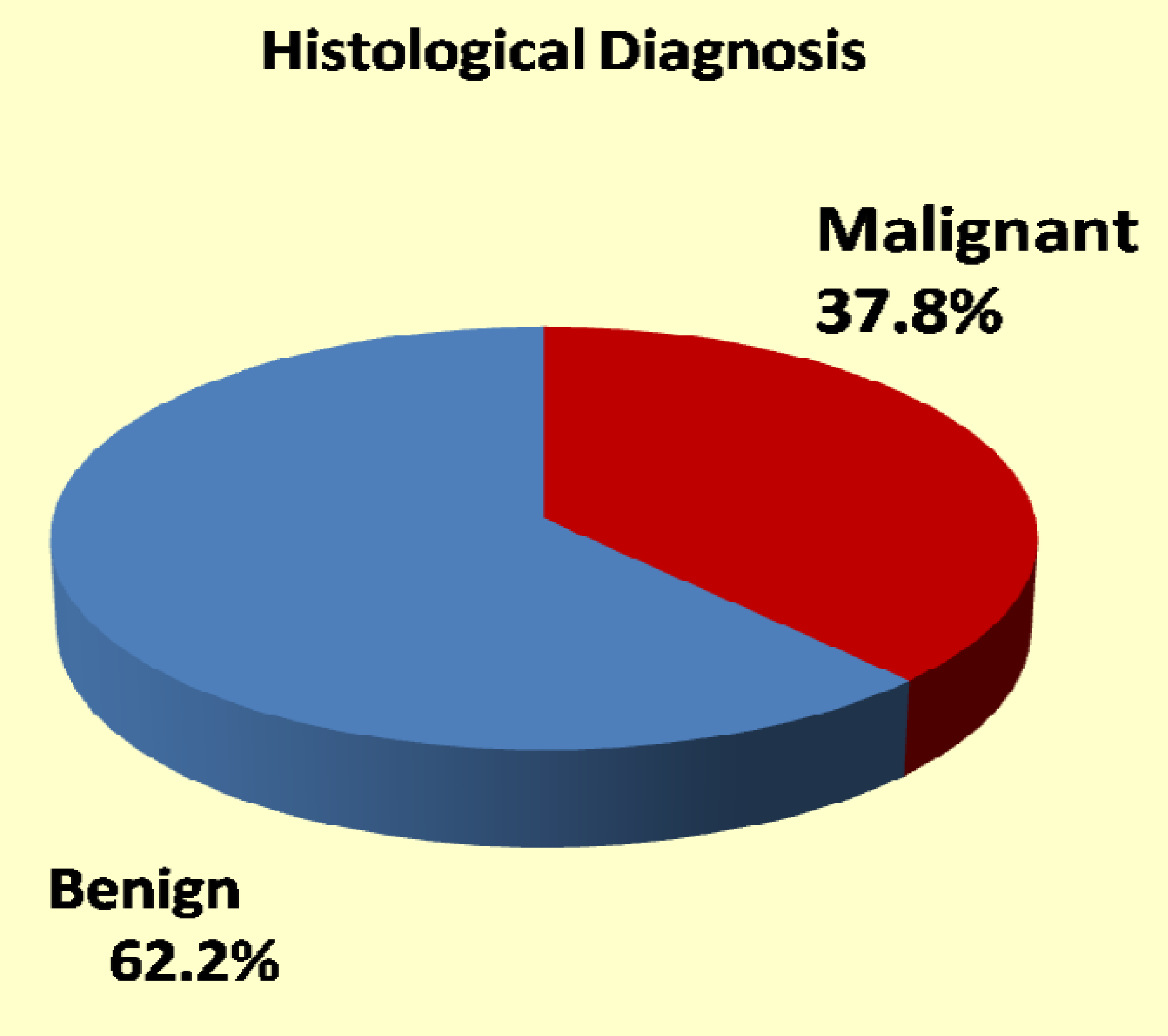

Figure 2: Histology outcomes
Table 2: Cytology/Histology Correlation

\begin{tabular}{|l|llllll|}
\hline \multicolumn{1}{|c|}{ Cytology } & & & & & \\
\hline Histology & Thy1 Thy2 Thy3 Thy4 Thy5 Total $(\%)$ \\
\hline Benign & 7 & 34 & 7 & 0 & 0 & $48(43.2 \%)$ \\
\hline Follicular Adenoma & 3 & 6 & 10 & 2 & 0 & $21(19 \%)$ \\
FC & 2 & 0 & 7 & 0 & 2 & $11(9.9 \%)$ \\
PTC & 0 & 1 & 4 & 5 & 13 & $23(20.7 \%)$ \\
MTC & 1 & 0 & 1 & 1 & 1 & $4(3.6 \%)$ \\
Pap microcarcinoma & 1 & 0 & 1 & 0 & 0 & $2(1.8 \%)$ \\
Metastasis & 0 & 0 & 0 & 1 & 1 & $2(1.8 \%)$ \\
Total & 14 & 41 & 30 & 9 & 17 & $111(100 \%)$ \\
\hline
\end{tabular}

\section{RESULTS}

Between January 2008 and December 2012, 567 thyroid FNAs were performed on 433 patients.

There were $349(80.6 \%)$ females and $84(19.4 \%)$ males, the ages of the patients ranged from 17 to 86 years.

The cytological diagnoses were as follows: Thy1 (non-diagnostic) in $63(11.1 \%)$ cases, Thy2 (benign) in 424 (74.8\%) cases, Thy3 (follicular lesion) in 54 (9.5\%) cases, Thy4 (suspicious for malignancy) in $9(1.6 \%)$ and Thy5 (malignant) in 17 (3\%) cases. Figure 1. Of 63 cases which were non-diagnostic, 25 had a repeat sampling, and of those a diagnostic aspirate was achieved in $84 \%$ ( $n=21$ ) of cases.

$80 \%$ of FNAs were performed under US guidance with onsite cytopathology evaluation, and the inadequacy rate was significantly lower in the US guided FNA compared to the free-hand aspirates $(8.7 \%$ vs. $15.7 \%$ respectively, $P<0.05)$ Table1.111 patients had either partial or total thyroidectomy, of which $69(62.2 \%)$ were benign and $43(37.8 \%)$ were malignant nodules .Figure 2 . Table 2 illustrates cytology/histology correlation.

The sensitivity and specificity for detecting neoplasia were $87.5 \%$ and $83 \%$, respectively.

\section{CONCLUSIONS}

Thyroid FNA is a reliable and accurate procedure in triaging patients with thyroid nodule for surgery. Our findings are consistent with the standard recommendations and published literature. The use of US guided FNA coupled with onsite evaluation by pathologist should be the standard practice in all cases of thyroid nodules referred for FNA in order to reduce inadequacy rate and improve accuracy.

References:1. Peros, P, et al. Guidelines for the management of thyroid cancer. Clinical Endocrinology, 2014; 81: 1-122. 5

2. Amrikachi M, Ramzy I, Rubenfeld S, Wheeler TM. Accuracy of fine-needle aspiration of thyroid. Arch Pathol Lab Med. 2001 Apr; 125(4):484-8.

3.Cross P, Chandra A, Giles T, et al. Guidance on the reporting of thyroid cytology specimens. London: Royal College of Pathologists; November 2009. 